\title{
Electric Machine Topologies in Energy Storage Systems
}

\author{
Juan de Santiago and Janaína Gonçalves de Oliveira \\ Division for electricity, Uppsala University \\ Sweden
}

\section{Introduction}

Energy storage systems based on pumped hydro storage, compressed air (CAES) and flywheels require electric machines working both as motors and generators. Each energy storage system has specific requirements leading to a variety of electric machine topologies. Hydro power and CAES stations have several configurations; they may have a turbinegenerator and an independent pump-motor group or a common turbine-motor/generator assembly, but in both cases the electric machines are coupled to turbines that are operated at constant speed and low electric frequency at steady state. Synchronous machines are the predominant technology for these applications.

Modern flywheel concepts based on a composite rotor driven by an electric machine started to be studied in the 1970s and 1980s. It is therefore a relatively new field of research based on the latest developments in strong light weight materials, new magnetic materials, magnetic bearings and power electronics. Despite the short history of the concept, there are already commercial applications and other potential applications have been identified such as space applications, Uninterruptible Power Supply (UPS), vehicles, grid quality enhancement, integration of renewable sources, etc. Flywheels are operated at high and variable speed and require specific machine topologies. Permanent magnet machines are preferred for vehicular flywheel applications (Acarnley et al., 1996), although inductance and reluctance topologies are applied for stationary flywheels.

Most common and promising types of machines use in energy storage systems discussed in this chapter are presented in Table 1.

\begin{tabular}{|l|l|l|}
\hline Constant Speed & Type & Properties \\
\hline \multirow{2}{*}{ Variable Speed } & Synchronous & $\begin{array}{l}\text { - Well established technology. } \\
\text { - Unlimited power rate. }\end{array}$ \\
\cline { 2 - 3 } & Induction & $\begin{array}{l}\text { - Robust and no iddle losses. } \\
\text { - Lower efficiency than other topologies. }\end{array}$ \\
\cline { 2 - 3 } & Permanent Magnet & $\begin{array}{l}\text { - Highest efficiency and power density. } \\
\text { - Sensitive to temperature. } \\
\text { - Higher material price. }\end{array}$ \\
\cline { 2 - 3 } & Reluctance & $\begin{array}{l}\text { - Robust and no iddle losses. } \\
\text { - Complex control. }\end{array}$ \\
\hline
\end{tabular}

Table 1. Electric machines used in Energy Storage applications. 
The purpose of this chapter is to discuss newly research threads and specific aspects in energy storage applications. For a general overview of the synchronous machine and a much detailed discussion of synchronous motor and generators, consult (Rashid, 2007), (Laughton \& Warne, 2003).

\section{Constant speed operation machines}

Due to the specific orography and water flow at the location, every hydro power station is unique and required tailor maid solutions in terms of water head and flow. Pumped hydro power plants may be equipped with an independent pump with a specific motor (generally an induction motor) or with reversible pump-turbine and a single motor/generator machine. Hydro turbines are directly coupled to the generator shaft without an intermediate gear box. The low speed operation of turbines forces a high number of poles in the electric machine in order to run at synchronous speed with the grid frequency.

Currently operated CAES are integrated in hybrid power plants. The air is compressed and stored in a reservoir when the electricity price is low, to be mixed with fuel and expanded in a conventional gas turbine at peak demand. Air pumps are operated at higher speeds than hydro pumps and therefore cylindrical rotor turbo machines are used in CAES power plants.

In both hydro power station and CAES, the turbine speed is constant at steady state operation. Synchronous machines are optimal for constant speed operation and dominate the high power station market.

\subsection{Synchronous machines}

In synchronous motor/generators, the rotor is wound and a DC current creates the rotor magnetic field. The rotor may be essentially described as an electromagnet. The magnetic field induced by a DC current is intrinsically invariant; the rotational movement makes the magnetic flux vary in time through the stator windings. The cross section of this kind of machines is shown in Fig. 1.

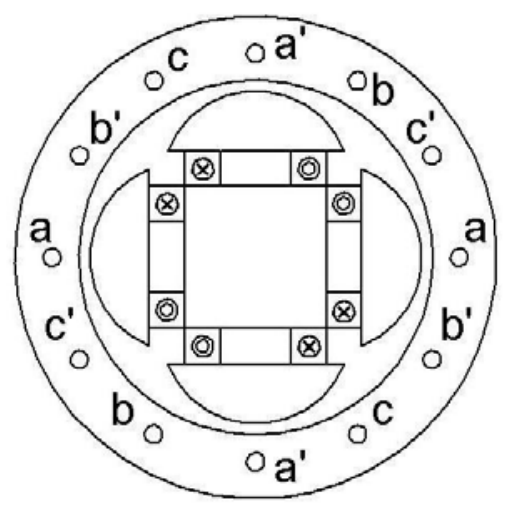

Fig. 1. Cross section of a three phase generator with a four salient pole rotor.

The mutual inductance between rotor and stator coils and pole saliency induces the electromotive force (e.m.f.) in the stator windings. For a three phase salient pole 
synchronous motor with negligible stator winding resistance, the electromagnetic power is expressed as (Laughton \& Warne, 2003):

$$
P=3 \cdot\left[\frac{V \cdot E}{X_{s d}} \cdot \sin (\delta)+\frac{V^{2}}{2} \cdot\left(\frac{1}{X_{s q}}-\frac{1}{X_{s d}}\right) \cdot \sin (2 \cdot \delta)\right]
$$

Where $V$ is the input phase voltage, $E$ is the e.m.f. induced by the rotor excitation flux or open circuit voltage, and $\delta$ is the power angle or angle between $E$ and $V ; X_{s q}$ and $X_{s d}$ are the synchronous reactances in the $d$ axis and $q$ axis. The equivalent one phase circuit of the synchronous generator may be represented as in Fig. 2.

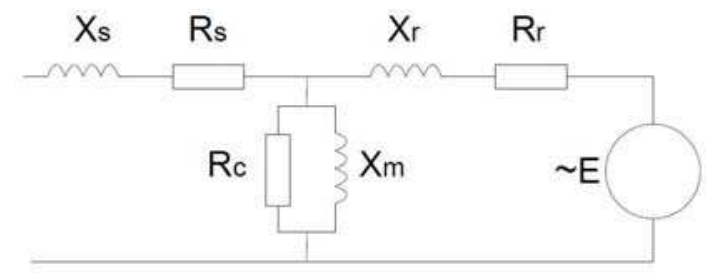

Fig. 2. One phase equivalent circuit of a synchronous generator

Even though synchronous generators are a mature technology and efficiencies up exceeding $98 \%$ have been reported, there are important research threads in this type of machines as described in following sections.

\subsubsection{High voltage insulation systems}

The stator is formed with a three phase winding. The armature windings in the stator are made of copper bars and packed as tight as possible to achieve a high filling factor (copper cross section/bar cross section). Due to the limited permeability of the laminated steel in the stator, the electric field induced in the stator bars depends on the vertical position of the slot. To equalize the voltage induced in each of the strands and eliminate circulating currents, they are usually transposed. Modern generators use the so called Roebel transposition. Every copper strand is insulated and strands are packed into bundles. High power rated generators have hollow copper tubes in the bundles for water or gas cooling. Insulation between copper bars is used to avoid short circuits but also to prevent corona effect. The insulation layers are made with different materials, traditionally based on mica. The insulation materials limit the generator voltage rates. There are several standard ratings (Changda et al., 1998). Even high power rated generators rarely exceed $25 \mathrm{kV}$ so transformers to couple the grid voltage are required. As an example, generators at the Three Gorges dam are rated over $700 \mathrm{MVA}$ at only $20 \mathrm{kV}$. These generator low voltage rates force high nominal currents that cause a significant amount of generator total losses.

A new technology proposes to wind the stator with high voltage, dielectric insulated cables, to withstand higher voltage ratings. This technology is known as Powerformer. High voltage operation increases overall efficiency and avoids the need of transformers. This technology is particularly interesting for energy storage systems with independent motor and generator machines in stationary systems. Motors and generators have different ratings and therefore different machine solutions may be adopted. 


\subsubsection{Multiphase systems}

Increasing the voltage is not the only strategy in the windings design to improve the performance of generators. Multiple phase systems and more than one set of windings in the stator have been proposed and currently under development. There are several advantages in multiple phase systems from the generators point of view. With multiphase systems, the magnetic field distribution in the air gap is more homogeneous and the power is distributed into more phases, reducing the current in every phase. Note that the reduction in current per phase does not reduce the current density nor the Joule losses as the slots in the stator have to be divided into more phases. The improvement of lower currents per phase relies in the lower power ratings in inverters and lower short circuit current in case of fault.

Designers are usually restricted to the three phase system as generators have to match the standard electric grid three phase system. Nevertheless, there are several threads of investigation in this field.

The Powerformer, discussed in section 2.1.1, has two sets of independent windings in the stator at different voltage levels. The main windings deliver power to the grid at high voltage, higher than the ancillary services. To supply different plant equipment, the Powerformer may have a devoted set of windings generating at lower voltage rate (ToumaHolmberg \& Srivastava, 2004).

The first application for two winding generator was developed as early as 1920's. In order to lower fault current in large generators and allow electrical segregation of bus sections in power stations, two identical layers of three-phase winding were proposed. Nowadays the same idea has been adopted to decrease the power rating of high power traction drives. Stators designed with a double star stator configurations require two power inverters but at half of the power rate.

The double winding configuration is also applied for inductance machines. In both cases the optimal angle between windings has been calculated in 30 electrical degrees (Fuchs \& Rosenberg, 1974). Ground of both star windings are connected, resulting an equivalent circuit as shown in Fig. 3.
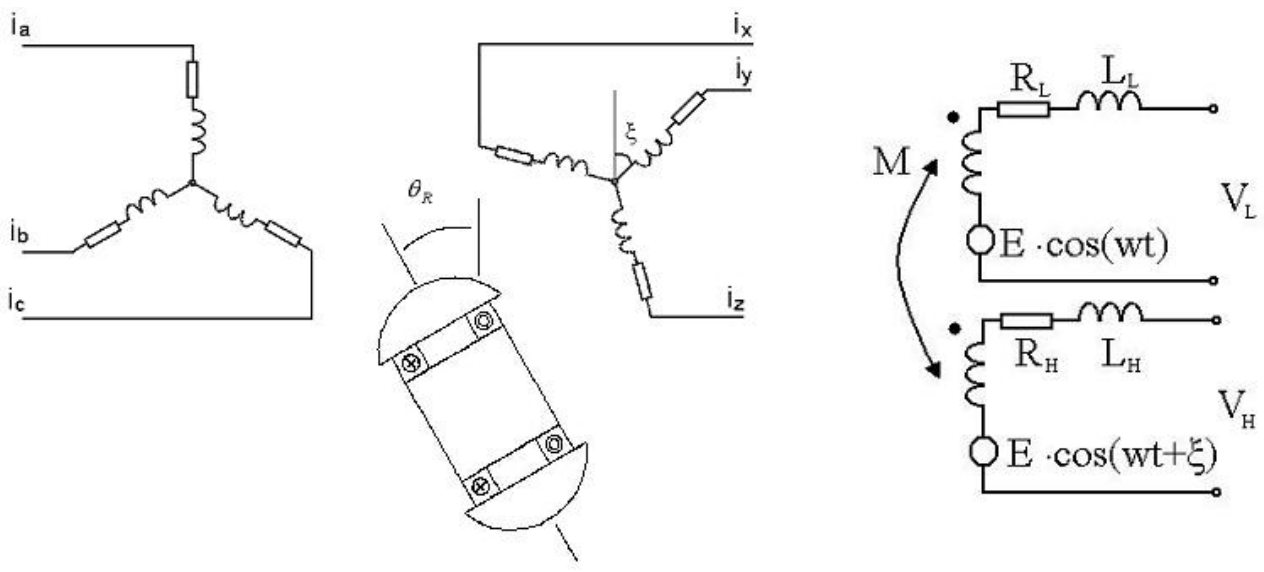

Fig. 3. Equivalent circuit and one phase equivalent circuit of a double star winding synchronous generator. 


\subsubsection{Excitation system}

The excitation system provides a DC current into the field winding of the generator to produce the magnetic field in the rotor. This apparently simple device has been classified in 12 different types of excitation systems by the IEEE standards (Kim, 2002), (IEEE Std 421.12007). The complexity of the excitation system lies on the control and regulation techniques. The field current regulates the no load voltage and the reactive power delivered by the generator. Modern excitation systems tend to avoid graphite brushes; the slip rings are replaced by a multiphase set of windings and the power is transfer to the rotor through the magnetic fields induced in the exciter stator. The AC currents in the rotor are rectified in rotating rectifiers mounted in the shaft and create the DC field current in the generator. The magnetic field in the excitation system stator is produced by a controlled current, either from a synchronous generator or a transformer connected to the generator's terminals. An alternator-rectifier exciter scheme is presented in Fig. 4. The AC exciter current is rectified in passive rectifier bridges. Controlled thyristors mounted on the rotor have been proposed, but this technology is still not commercially developed as it significantly increases the generator costs.

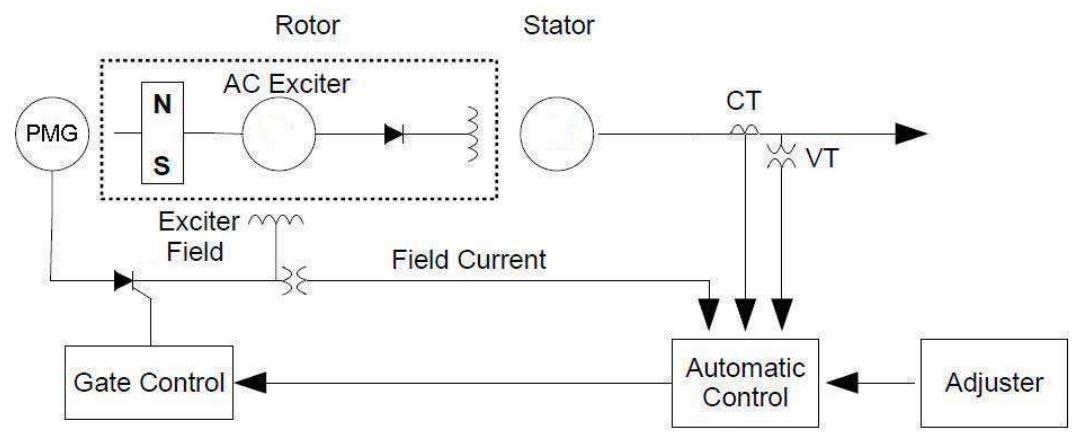

Fig. 4. Alternator-rectifier exciter employing rotating non-controlled rectifiers.

Standard excitation systems are based on a DC current that flows through a single phase field winding, but more complex configurations are also possible. Two phase excitation systems have been proposed to create a rotating magnetic field in the rotor. The magnetic field rotational speed that would see the stator windings is the addition of the mechanical rotational speed plus the magnetic field circulation around the rotor. This machine is called asynchronised synchronous generator. They are designed to operate up to a maximum slip of $20 \%$. The speed regulation is particularly interesting in hydro generators with wide range of water head changes and gas turbines to operate them with a low inertia constant (Mamikoniants et al., 1999).

Multiple phase rotors may be also be designed to improve the magnetic field distribution in the airgap. The magnetic field distribution in simple or double phase excitation systems rely on the symmetry of the rotor and stator geometry. The excitation field current provides the magnetomotive force in the magnetic field circuit that flows through rotor and stator. An eccentricity or miss aliment in the rotor would create a non uniform magnetic reluctance and therefore unsymmetrical magnetic field distributions. The region where the magnetic field increases suffers saturation in the teeth steel which leads to harmonics in the e.m.f., 
higher hysterics losses and higher current in dumping bars. Eccentricity in the rotor leads also to unbalanced radial forces and wear (Lundin \& Wolfbrandt, 2009). Multiple and independent field winding phases controlled by rotating thyristors may be a solution for rotor eccentricity.

\section{Variable speed operation machines}

Flywheel energy storage systems are base on the variation of rotational energy with rotational speed. Almost constant speed flywheels with synchronous generators, with a speed deviation of around $2 \%$ of the nominal speed, have been studied, but the high moment of inertia required make this configuration impractical (Carrillo et al., 2009). Therefore flywheels are designed to vary speed with a maximum nominal speed of about twice the minimum speed, and require variable speed machines. The speed range varies from applications, but generally nominal speeds are over the standard 50 or $60 \mathrm{~Hz}$. Electronic converters are required to couple flywheels to the electric grid.

The flywheel market is not mature and lacks of standardization. Brushless machines are preferred in flywheel applications, but there is still a great variety of machine topologies and system parameters discussed. The machine configurations may be classified into: induction, reluctance and permanent magnet machines.

\subsection{Permanent Magnet machines}

High coercitive materials have been developed and applied only for the last 20 years and the technology is still evolving. The rotor is shelf excited with Permanent Magnet (PM) excitation and allows high power density and efficiency as it lacks excitation losses (Gieras \& Wing, 2002). These properties make PM machines preferred in many vehicular applications.

\subsubsection{PM machine topologies}

There is a great variety of permanent magnet arrangements to increase the magnetic field in the airgap, to obtain a sinusoidal distribution and to reduce eddy current losses in the magnets that may lead to reduction in performance and permanent demagnetization.

Regarding the flux path, most common types of machines have radial or axial flux configurations. Other topologies have been described without much widespread as conical, transversal or spherical. Magnets may be surface mounted or internal mounted on the rotor surface. The magnets are mounted on the rotor in different ways. Axial-flux machines usually have their magnets mounted on the surface of the rotor, while radial-flux machines may have the magnets either surface mounted or internal mounted (Kolehmainen \& Ikäheimo, 2008). Internal mounted magnet machine properties vary with the geometry and configuration of the rotor. A magnetic material conducts the magnetic flux so the magnets are isolated from the harmonics produced by the stator. The iron bridges may be mechanized to obtain a sinusoidal magnetic flux distribution and produces a significant saliency. The saliency affects the performance of electric motors as lead to higher synchronous reactance in the direct axis $\left(X_{s d}\right)$ than in the quadrature axis $\left(X_{s q}\right)$. Iron bridges between and over the magnets produce a leakage in the magnetic flux, despite of the complexity of the arrangement.

The differences in geometry between surface mounted and Internal mounted magnets are clearly shown in Fig. 5. 

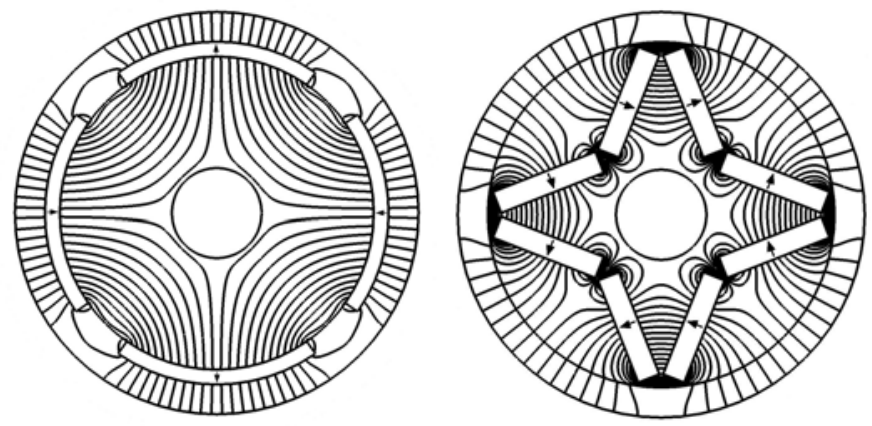

Fig. 5. Rotors with surface mounted (left) and internal mounted (right) magnets with the magnetic field lines induced in the airgap and in the rotor steel.

\subsubsection{Halbach PM array}

A special magnet configuration, both for axial and radial flux machines is the Halbach arrangement. For the ideal Halbach array, the magnets are combined in such a way that the magnetic field intensity is cancelled on one side of the array. With the Halbach magnet array no magnetic back-iron is needed and higher specific torques may be achieved. The simplest Halbach array configuration, presented in Fig. 6, conbines radial and azimutal magnets.
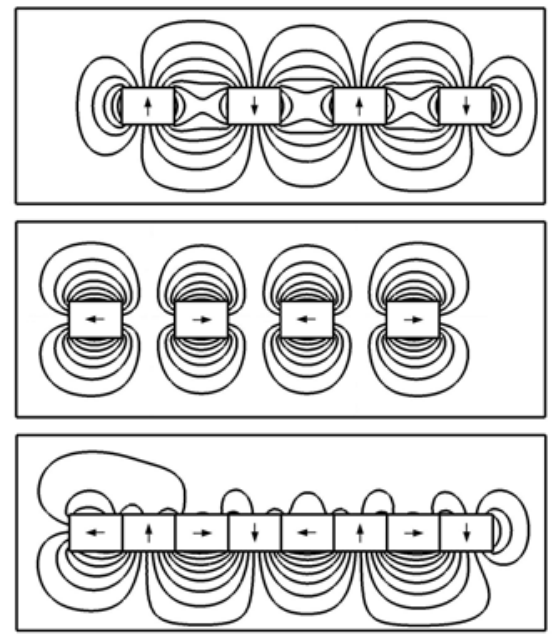

Fig. 6. Halbach array configuration. Magnetic potential in a radial magnet array (top), azimutal magnet array (middle) and composition of both in a Halbach array (bottom).

Electric machines with Halbach PM arrays have comparable performance as machines with a magnetic back yoke (Ofori-Tenkorrang \& Lang, 1995) and an intrinsic sinusoidal magnetic field distribution in the airgap. The mass inertia in machines without iron back yoke is also lower, but the dinamic perfornmance is nor relevant for machines coupled to a high moment of inertia flywheel. 
The size of high speed machines is usually limitd by the mechanical strenght of the magetic iron in the back yoke. Halbach arrays allow machine topologies without back yoke and self magnetic shielded, and some authors claim to be the best solution high speed machies for flywheel aplications (Post et al., 1993).

\subsubsection{Coreless machines}

Losses in the iron core of electric machines increase dramatically with electric frequency. This is the reason why coreless machine topologies are raising interest for high speed machines. With the development of new permanent magnet machines high magnetic fluxes may be achieved in the airgap of electric machines, and expected to reach higher values than traditional slotted machines (Santiago \& Bernhoff, 2010).

Traditionally, stator windings are placed in laminated steel slots. The stator teeth reduce the airgap and therefore the magnetic reluctance in the magnetic circuit. Lower magnetic reluctance leads to less magnetic material, more compact designs and higher power density. There is a limit in the reduction of the airgap. Without considering the technical feasibility of construction, smaller airgaps have also some disadvantages. The magnetic flux distribution in the airgap becomes squared and cogging torque increases. Losses in the stator teeth also increase with smaller airgaps due to the increase in the harmonic content in the magnetic flux density.

There are two stator configurations without teeth. In slotless machines the windings are directly placed over the stator yoke. The magnetic flux path that goes through the stator back yoke has a substantially less density than in stator teeth (Wallmark et al., 2009).

In the ironless or coreless configuration, the back iron yoke rotates simultaneously with the rotor, so the magnetic circuit does not produce hysteresis or eddy current losses. The coreless stator reduces the iron loss, especially at high-speed operation (Ooshima et al., 2006). An ironless axial flux and a radial flux machine with an outer rotor configuration are presented in Fig. 7.
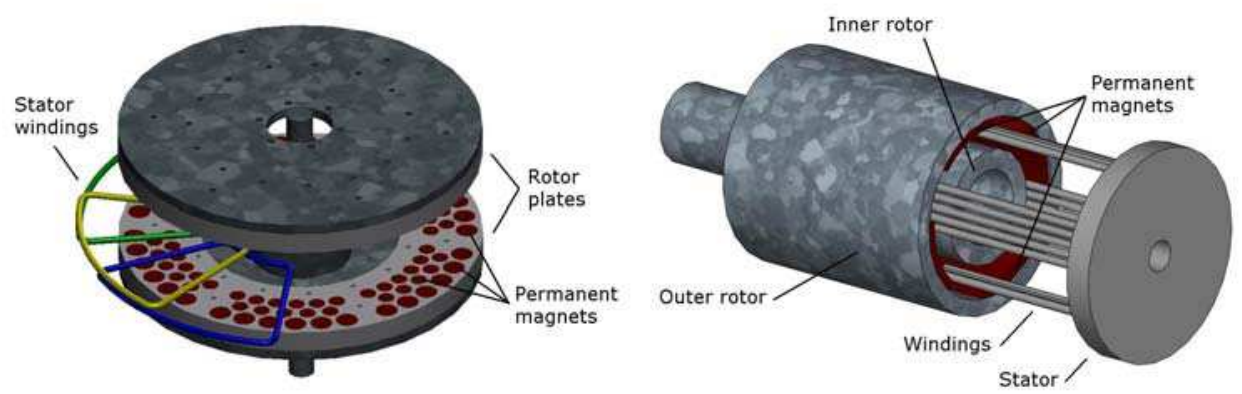

Fig. 7. Ironless axial and radial flux machines with an outer rotor configuration.

\subsubsection{PM machine control}

High coercitive materials such as Neodymium Iron Boron magnets have a very low magnetic permeability, close to air. This leads to very low inductance in the windings, especially for slotless machines. Low inductance machines require current control to reduce current ripple (Su \& Adams, 2001). 
For high performance motion control applications, the closed loop control with vector control should be incorporated to achieve high dynamic performance in position, speed and torque control (Jahns, 1997). However, when high dynamic performance is not a demand, simple $\mathrm{V} / \mathrm{f}$ control strategies may be sufficient to obtain the required control performance.

\subsubsection{Mathematical Model of a PM motor drive}

The DQ transformation expresses the three-phase stationary coordinate system into the $d-q$ rotating coordinate system (Low et al., 1995). Permanent magnet synchronous motors (PMSM) are described by a multivariable, coupled and nonlinear equations. The $d-q$ transformation is used to transform these nonlinear equations into a simplified linear state model. The voltage equations of the PMSM in the rotating reference frame are:

$$
\begin{gathered}
v_{d}=R \cdot i_{d}+L_{d} \cdot \frac{d i_{d}}{d t}-\omega \cdot L_{q} \cdot i_{q} \\
v_{q}=R \cdot i_{q}+L_{q} \cdot \frac{d i_{q}}{d t}+\omega \cdot L_{d} \cdot i_{d}+\omega \cdot \lambda_{r}
\end{gathered}
$$

The electromagnetic torque can be written as

$$
T_{e}=\frac{3}{2} \cdot \frac{p}{2} \cdot\left[\lambda \cdot i_{q}+\left(L_{d}-L_{q}\right) \cdot i_{q} \cdot i_{d}\right]
$$

where $v_{d}, v_{q}, i_{d}$, and $i_{q}$ are the stator voltages and currents, respectively. $R$ is the stator resistance, $L_{d}$ and $L_{q}$ are the $\mathrm{d}-\mathrm{q}$ axis stator inductances, respectively; $\lambda_{r}$ is the rotor flux, $T_{e}$ is the electromagnetic torque and $p$ is the number of poles.

The electromechanical equation of a PMSM is given by:

$$
\frac{p}{2} \cdot\left(T_{e}-T_{l}\right)=J \cdot \frac{d}{d t} \cdot \omega+B \cdot \omega
$$

where $T_{l}, \omega, J$ and $B$ represent the load torque, the electrical rotor speed, the inertia and the friction coefficient of the motor, respectively.

\subsubsection{Scalar V/f Control}

The simplest way to control a PMSM for variable speed applications is through the open loop scalar control. It is used in applications where information about the angular speed is not needed. It is suitable for a wide range of drives as it ensures robustness at the cost of reduced dynamic performance. The supply voltage frequency is changed independently from the shaft response (position and angular speed). The magnitude of the supply voltage is changed according to the frequency in a constant ratio. Then the motor is in the condition where the magnetic flux represents the nominal value and the motor is neither overexcited nor underexcited. The main advantage of this simple method is the absence of a position sensor. The control algorithm does not need information about the angular speed or actual rotor position. On the contrary, the big disadvantages are the speed dependence on the external load torque, mainly for Induction Machines, and limited dynamic performances (Perera et al., 2002). Despite of its simplicity, scalar V/f control is used in flywheel applications (Sun et al., 2009). 
The machine rotational speed $\omega$ varies proportionally with the frequency of the input signal, $f_{s}$, as follows:

$$
\omega=\frac{2 \pi \cdot f_{s}}{p p}
$$

where $p p$ is the number of pole pairs of the machine.

The magnetic flux can, if the stator resistance is neglected, be expressed as:

$$
\lambda_{s}=\frac{V_{\varphi}}{\sqrt{2} \pi \cdot f_{s} \cdot N \cdot k_{w}}=\text { Const } \cdot \frac{V_{\varphi}}{f_{s}}
$$

So, in order to avoid variations in the stator flux (which could cause the motor to be overexcited or under excited), the voltage-to-frequency ratio is kept constant, hence the name $\mathrm{V} / \mathrm{f}$ control.

If the ratio is different from the nominal one, the motor will become overexcited. This means that the magnetizing flux is higher than the constant ratio $V / f$, or underexcited, which happens because voltage is kept constant and the value of the stator frequency is higher than the nominal one.

\subsubsection{Vector Control}

Vector control (Field Oriented Control) of AC machines, as a novel approach in electrical drives, provides very good performance in dynamic responses in comparison with the scalar control. Vector control eliminates almost all the disadvantages of constant $\mathrm{V} / \mathrm{f}$ control. The main idea of this method is based on controlling the magnitudes and angles of the space vectors.

Vector control of PMSM allows, by using $d-q$ components, separating closed loop of both flux and torque (Stulrajter et al., 2007), hence, achieving a similar control structure to that of a separately excited DC machine. The electromagnetic torque can be expressed in $d-q$ components according to nonlinear model of PMSM, as seen in equation 4 . The torque depends on the rotor type and its inductances $L_{d}, L_{q}$ and on permanent magnets mounted on the rotor.

The surface mounted (non-salient) PMSM, it can be taken that $L_{d}=L_{q}$ and the maximum torque per ampere for this machine is obtained by making $i_{d}=0$, or, in other words, by maintaining the torque angle at $90^{\circ}$ what produces a maximum quadrant current $i_{q}$.

It follows from equation 4 that if a non-salient machine is considered the electromagnetic torque can be expressed as

$$
T_{e}=\frac{3}{2} \cdot \frac{p}{2} \cdot \lambda \cdot i_{q}
$$

Vector control structures for a wide variety of PMSM drivers have the same characteristic. The most popular control technique is the cascaded one using classical techniques to achieve torque, speed and position control in PMSM motion control system, as seen in Fig. 8 .

Fig. 8 shows a closed speed feedback loop around the inner torque/current loop. The torque request is generated by the speed controller and, by keeping $i_{d}$ equal to zero, the phase stator current will be placed in the quadrature axis and the maximal driving torque will be achieved. 


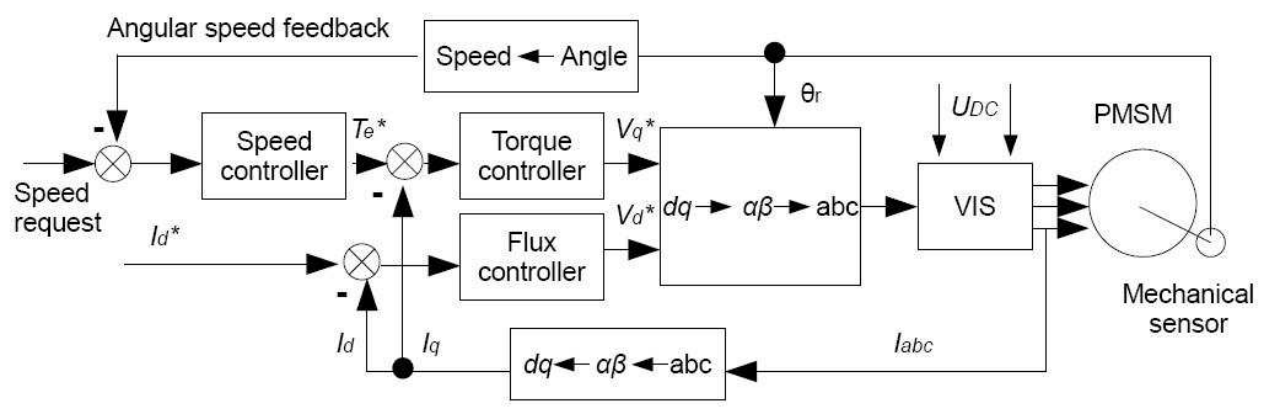

Fig. 8. Typical cascaded control structure for PMSM drivers.

\subsubsection{Variable geometry for variable speed operation}

Magnetization in permanent magnets is constant and can not be used as a control parameter as synchronous machines regulate the field current. Therefore the voltage increases linearly with speed, in absence of magnetic saturation. Variable geometry topologies have been proposed to operate permanent magnets in a wide speed range with constant back e.m.f.

There are two different variable geometries strategies reported for variable speed operation. The solution proposed in (Javadi \& Mirsalim, 2010) is based on a double-stator structure with variable stator geometry. The concept has been applied in an axial flux generator with a three stator and a coreless double-stator structure; one is stationary and the other rotate to achieve field weakening.

The field weakening may be achieved by increasing the airgap. This field weakening strategy may only be applied in axial flux machines, as the radius of radial flux machines is inherently constant. In axial flux machine with one stator and one rotor configuration, a mechanism that separates the rotor from the stator as the speed increases may be implemented. With the same excitation in the rotor, a higher airgap reduces the magnetic flux through the stator. The back e.m.f. amplitude is kept constant for a high range of speeds, as the electrical frequency increases linearly with the speed. An advantage in this system is that the efficiency is very high for a wide range of operational speeds. The hysteretic and eddy current losses are proportional to the square of the speed, but also to the magnetic flux. At high speed the frequency increases, but the magnetic field is reduced, counteracting this effect. Efficiencies of $98 \%$ at $10.000 \mathrm{rpm}$ with this system have been reported (Nagaya et al., 2003).

\subsection{Induction machines}

About $65 \%$ of the worlds electricity production in the world is consumed in induction motors. They are ussually preferred because they are inexpensive, require little maintenance and are reliable. Asynchronous machines have a very mature and standarized technology; EPA in the US and CEMEP in the European Union have a general efficiency clasification system. The result of adapting these directives will lead to an increase in the efficiency and a shift to high efficiency machines with a signifficant impoct in the market for the next years (Chitroju, 2009). The equivalent circuit of an induction machine is presented in Fig. 9 where the influence of the slip is clearly seen. 


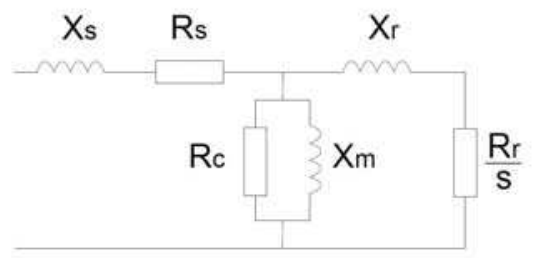

Fig. 9. Excitation system description.

Variable frequency AC drives are used for variable speed operation. The inverter allows a great flexibility of power and speed range but the power electronic rating requiered increases the equipment costs for high power aplications. Due to the system simplicity, asynchronous machines are used in stationary flywheel energy storage low power applications (Cheng et al., 2008), (Kato et al., 2009).

A strategy to reduce the power rating of the power electronics consist of using two sets of windings in the stator. One set would be directly connected to the grid and the other would be driven by an inverter. This is the idea behind Brushless Doubly Fed Induction Machine (BDFIM) topology proposed for a regular 2:1 speed range ratio in a flywheel operation (Tazil et al., 2010).

\subsubsection{Induction machines control}

One way of controlling AC motors for variable speed applications is through the open loop scalar control, which represents the most popular control strategy of squirrel cage AC motors.

Most of the concepts in control estimation for permanent magnets synchronous motors are also applicable to induction motor drives. Open loop scalar control is broadly used in induction motors drives (Finch, 1998), (Luo et al., 2007), (Srilad et al., 2007), however, its importance is diminishing because of the superior performance of vector controlled (or field oriented controlled) drives (Khambadkone \& Holtz, 1991), (Kim et al., 1986), (Rowan et al., 1982), (Xu et al., 1988).

Scalar- and vector-controlled drives have already been discussed in Section 3.1.4. An advanced scalar control technique, know as direct torque and flux control (DTC) (Habetter, 1992) was introduced in the mid-1980s, being claimed to have nearly comparable performance with vector-controlled drives. DTC has recently been introduced in commercial induction motor drives thus creating a wide interest.

\subsubsection{Direct Torque and Flux Control}

Direct Torque Control (DTC) uses an induction motor model to predict the voltage required to achieve a desired output torque (Takahashi \& Noguch, 1986). Differently from vector control, stator flux and output torque are estimated by using only current and voltage measurements according to equations 9 and 10:

$$
\begin{aligned}
& \bar{\lambda}_{S}=\left(\bar{V}_{S}-r_{S} \cdot \bar{I}_{S}\right) \cdot d t \\
& T_{e m}=\frac{3}{2} \cdot \frac{p}{2} \cdot\left(\bar{\lambda}_{S} \times \bar{I}_{S}\right)
\end{aligned}
$$


where $\bar{\lambda}_{S}$ is the stator flux vector, $T_{e m}$ is the produced torque, $p$ is the number of poles. $\bar{V}_{S}$, $\bar{I}_{S}$ and $r_{s}$ are the stator voltage, current and resistance, respectively.

Combining equations 9 and 10 to the equations that describe the equivalent circuit of an induction motor, expressions for the change in torque and flux are obtained. These equations can be solved to find the smallest voltage vector, $\bar{V}_{S}$, required to drive both the torque and flux to the demand values.

Fig. 10 shows the schematic of the basic functional blocks used to implement Direct Torque Control:

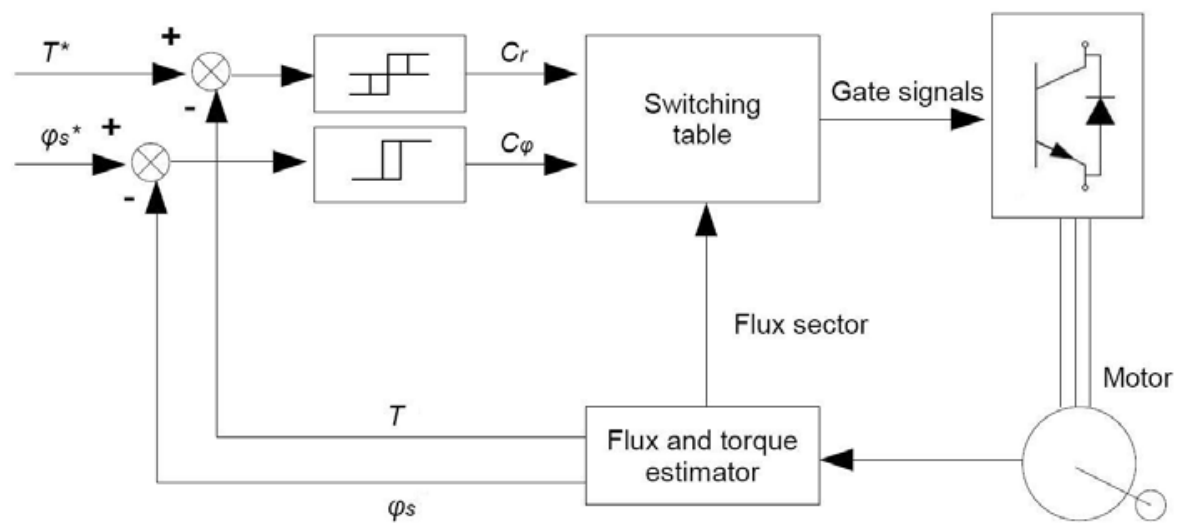

Fig. 10. Basic Direct Torque Control scheme.

Latest research on DTC has focused on decreasing the torque ripple and obtaining faster transient response to the step changes in torque during start-up (Cadasei \& Serra, 2002), (El afia et al., 2005). Also, the combination of DTC and intelligent techniques such as fuzzy logic or artificial neural network has been attracting the attention of many scientists from all over the world (Toufouti et al., 2006), (Toufouti et al., 2007).

\subsubsection{Brushless Doubly Feed Induction Machines (BDFIM)}

BDFIM machines are gaining attention in wind power generation as limmited variable speed is required. The BDFIM has similar rotor as the singel feed traditional induction machine. It is a solid piece of laminated steel with conducting bars, but instead been shortcircuited forming a cage, the end winding conections form poles as presented in Fig. 11. The stator structure do not differe from the induction machine. The difference is that the BDFIM has two sets of insulated stator windings of different pole numbers. One primary winding (or power winding) is grid connected and the secondary winding (or control winding) is driven by a converter that regulated the frequency. The machine speed is the composition of the primary and secundary winding frequencies.

The power in the BDFIM is partially driven by the secundary winding, but most of it flows directly from the rotor to the power winding, reducing the power electronic rating till only $25 \%$ of the requierements of a single feed induction machine (Klempner \& Kerszenbaum, 2004). The BDFIM has been proposed and implemented for flywheel applications with promising results (Wu et al., 2009). 


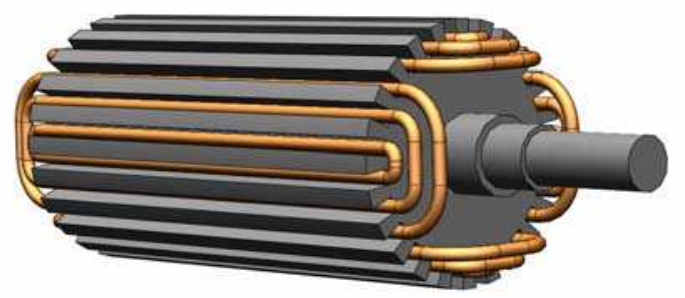

Fig. 11. Four pole rotor configuration of a BDFIM.

\subsection{Reluctance machines}

The main characteristic of reluctance machines is that the rotor is built with salient poles. The rotor lacks excitation and the torque is produced solely by the difference between the direct axis and quadrature axis synchronous reactance. The power is therefore obtained by the second term of equation 1. A figure of merit for the synchronous reluctance machine is the ratio of $d$ to $q$ axis inductance.

Reluctance machines have some favourable characteristics for flywheel energy storage systems. It lacks excitation currents that allow low idle losses. The rotor is robust and allows high speeds operations. It has great acceptance in UPS systems and other stationary applications as stand alone flywheels to handle voltage sags and power disruptions that last less than 5 seconds (Park et al., 2008). This reduces the number of charge/discharge cycles and increases the lifespan of the battery pack. The equivalent circuit of a reluctance machine is presented in Fig. 12.

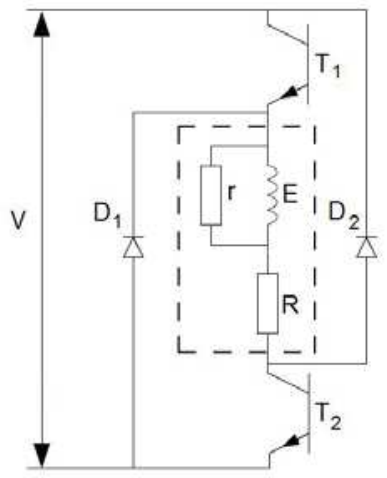

Fig. 12. One phase equivalent circuit with switching elements of a reluctance motor.

Reluctance machines may be divided into switched-reluctance machines (SRM) and synchronous reluctance machines (Syncrel).

The Syncrel has distributed windings in the stator, similar to synchronous and inductance machines. It lacks of any source of flux on the rotor, and therefore the power density is lower than in synchronous or induction machines. To increase the power density and efficiency, permanent magnet may be placed in the rotor. This hybrid type of machine is called permanent magnet assisted synchronous reluctance motor. 
The SRM has concentrated windings and a saliency structure both in rotor and stator, that is why there are also called doubly salient variable-reluctance machines. The structure of the machines is similar to the stepper motor. There are many combinations in the number of stator phases and rotor poles. The simplest consists of only one phase with a considerable cogging torque. The most common configuration has a four-phase and eight rotor poles and six stator poles configuration. At least three phases are required for a four quadrants operation (both motoring and generating) (Rashid, 2007).

Reluctance machines may have two sets of independent windings in the stator. The Double Feed Reluctance Machine (DFRM) has not been commercially developed yet, but is has the same potentially advantages as the DFIM. The DFRM has two sinusoidal distributed stator windings as the DFIM discussed in 3.2.2. The power electronics require lower power ratings than single feed machines and also allow variable speed operation while the power winding is directly coupled to the grid frequency (Valenciaga \& Puleston, 2007). The main drawback of this technology is the low torque per volume, lower than an equivalent synchronous reluctance (Syncrel) or a cage induction machine (IM) (Jovanovic, 2009).

\section{Conclusion}

Energy storage development is essential if intermittent renewable energy generation is to increase. Pumped hydro, CAES and flywheels are environmentally friendly and economical storage alternatives that required electric motor/generators. The popularization of power electronics is relatively new and therefore the technology is still under development. There is not a clear winner when comparing technologies and therefore the optimal alternative depends on the specific requirements of the application.

In this chapter the main electric machine topologies for energy storage are presented. The discussion is focused on the applicability and also on the latest research threads and state of the art.

\section{References}

Acarnley, P.P.; Mecrow, B.C.; Burdess, J.S.; Fawcett, J.N.; Kelly, J.G. \& Dickinson, P.G. (1996), Design principles for a flywheel energy store for road vehicles, IEEE Trans. on Industry Applications, Vol. 32 , Issue: 6, pp. 1402 - 1408, 1996.

Boger, M. S.; Wallace, A. K. \& Spee, R. (1996), Investigation of Appropriate Pole Number Combinations for Brushless Doubly Fed Machines Applied to Pump Drives, IEEE Trans. On Industry Applications, Vol. 32, Issue 1, pp. 189-194, 1996.

Carrillo, C., Feijóo, A. \& Cidrás J. (2009), Comparative study of flywheel systems in an isolated wind plant, Renewable Energy, Vol. 34, Issue 3, pp. 890-898,March 2009.

Casadei, D. \& Serra, G. (2002), Implementation of direct Torque control Algorithm for Induction Motors Based on Discrete Space Vector Modulation, IEEE Trans. Power Electronics, Vol. 15, No. 4, 2002.

Changda, S.; Guobiao G. \& Shunchao, Y. (1998), Evaporative cooling technology more suitable for the Three Gorges' generators, Proceedings of POWERCON '98. International Conference on Power System Technology, pp 1025-9, Vol. 2, 1998.

Cheng, M., Kato, S., Sumitani, H., \& Shimada, R. (2008), A novel method for improving the overload capability of stand-alone power generating systems based on a flywheel 
induction motor, Proceedings of the IEEE Annual Power Electronics Specialists Conference, pp. 3677-3683, 2008.

Chitroju, R. K. S. (2009), Improved Performance Characteristics of Induction Machines with Non-skewed Asymmetrical Rotor Slots, Licentiate thesis, Royal Institute of Technology (KTH), Stockholm, Sweden, 2009. ISBN 978-91-7415-453-5.

El afia, A., Khafallah, M., Cheriti, A., Elmoussaoui, B. \& Saad, A. (2005), A simple direct torque fuzzy control of induction motor using space vector modulation, EPE Journal, Vol. 15, No. 2, pp. 25-30, 2005.

Finch, J. W. (1998), Scalar and vector: a simplified treatment of induction motor control performance, Proceedings of the IEE Colloquium on Vector Control Revisited, IEE Digest, Vol. 1998, Issue 199, pp. 2/1-4, 1998.

Fuchs, E. F. \& Rosenberg L. T. (1974), Analysis of an alternator with two displaced stator windings, IEEE Trans. Power Application Systems, Vol. PAS-93, pp. 1776-1786, 1974.

Gieras, J. F. \& Wing, M. (2002), Permanent Magnet Motor Technology Revised, CRC, 2nd edition, January 15, 2002.

Habetler, T. G., Profumo, F., Pastorelli, M. \& Tolbert, L.M. (1992), Direct Torque Control of Induction Machines using Space Vector Modulation, IEEE Trans. Industry Applications, Vol. 28, No. 5, 1992.

IEEE Std 421.1-2007, IEEE Standard Definitions for Excitation Systems for Synchronous Machines.

Jahns, T. M. (1997), Variable Frequency Permanent Magnet AC Machine Drives, Chapter 6 in Power Electronics and Variable Frequency Drives, Technology and Applications, Ed. IEEE Press, ISBN o-7803-1061-6, 1997.

Javadi, S. \& Mirsalim, M. (2010), Design and Analysis of 42-V Coreless Axial-Flux Permanent-Magnet Generators for Automotive Applications, IEEE Trans. on Magnetics, Vol. 46, Issue 4, pp. 1015-1023, April 2010.

Jovanovic, M. (2009), Sensored and sensorless speed control methods for brushless doubly fed reluctance motors, IET Electric Power Applications, Vol. 3, Issue 6, pp. 503-513, November 2009.

Kato, S., Takaku, T., Sumitani, H. \& Shimada, R. (2009), Development of voltage sag compensator and UPS using a flywheel induction motor and an engine generator, Electrical Engineering in Japan, Vol. 167, No. 1, pp. 74-81, 15 April 2009.

Khambadkone, A. M. \& Holtz, J. (1991), Vector controlled induction motor drive with a selfcomissioning scheme, IEEE Trans. on Industrial Electronics, Vol. 38, p 322-327, 1991.

Kim, C. (2002), Performance Analysis for the Modified Excitation System of Synchronous Machine Connected to HVDC System, KIEE International Transaction on Electrical Machinery and Energy Conversion Systems, Vol. 2B, No. 3, 2002, pp. 109-114, 2002, ISSN 1598-2602.

Kim, Y. R., Sul, S. K. \& Park, M. H. (1986), Speed sensorless vector control of induction using extended Kalman filter, IEEE Trans. on Industrial Applications, Vol. 30, pp 1225-1233, 1986.

Klempner, G. \& Kerszenbaum, I. (2004). Operation and maintenance of large turbogenerators, IEEE Press Series on Power Engineering, ISBN 0-471-61447-5, New Jersey.

Kolehmainen, J. \& Ikäheimo, J. (2008), Motors With Buried Magnets for Medium-Speed Applications, IEEE Trans on Energy Conversion, Vol. 23, No. 1, March 2008. 
Laughton, M.A. \& Warne, D.F, (2003), Electrical Engineer's Reference Book, 16th Edition, Chapter 28, ISBN 13: 9780750646376, Elsevier, 2003.

Low, K. S., Rahman, M. F. \& Lim, K. W. (1995), The d-q transformation and feedback linearization of a permanent magnet synchronous motor, Proceedings of International Conference on Power Electronics and Drive Systems, Vol. 1, pp. 292-296, 1995.

Lundin U \& Wolfbrandt A (2009), Method for Modeling Time-Dependent Nonuniform Rotor/Stator Configurations in Electrical Machines, IEEE Trans. on Magnetics, Vol. 45, Issue 7, pp. 2976-2980, 2009.

Luo, H., Wang, Q., Deng, X. \& Wan. S. (2007), A novel V/f scalar controlled induction motor drives with compensation based on decoupled stator current, IEEE International Conference on Information Technology, pp. 1989-94, 2007.

Mamikoniants, L.G., Shakaran, Y.G.; Vinitsky, Y.D., Kauffmann, J.M. \& Barbier, G. (1999). Asynchronized synchronous machine application in the power systems operational experience and prospects, Proceedings of International Electric Machines and Drives Conference IEEE IEMDC'99, pp. 746 - 748, Seattle, Washington, USA, May 1999.

Nagaya, S., Kashima, N., Kawashima, H., Kakiuchi, Y., Hoshino, A. \& Isobe, S. (2003), Development of the axial gap type motor/generator for the flywheel with superconducting magnetic bearings, Physica C- Superconductivity and its Applications, Vol. 392, pp. 764-768, 2003.

Ofori-Tenkorrang, J. \& Lang, J.H. (1995), A Comparative Analysis of Torque Production in Halbach and Conventional Surface-Mounted Permanent-Magnet Synchronous Motors, Proceedings of 13th IEEE Industry Applications Conference, IAS 1995.

Ooshima, M., Kitazawa, S., Chiba, A., Fukao, T. \& Dorrell, D.G. (2006), Design and analyses of a coreless-stator-type bearingless motor/generator for clean energy generation and storage systems, IEEE Transactions on Magnetics, Vol. 42, No. 10, pp. 3461-3, Oct. 2006.

Park, J., Kalev, C. \& Hofmann, H.F. (2008), Control of High-Speed Solid-Rotor Synchronous Reluctance Motor/Generator for Flywheel-Based Uninterruptible Power Supplies. IEEE Trans. on Industrial Electronics, Vol. 55, No. 8, pp. 3038-46, Aug. 2008.

Perera, P. D. C., Blaabjerg, F., Pedersen, J. K. \& Thogersen, P. (2002), A sensorless, stable V/f control method for permanent-magnet synchronous motor drives, Proceedings of Applied Power Electronics Conference and Exposition, Vol. 1, pp. 83 - 8, 2002.

Post, R.F.; Fowler, T.K. \& Post, S.F., (1993), A High-Efficiency Electromechanical Battery, Proceedings of the IEEE, Vol. 81, No. 3, pp. 462-74, March 1993.

Rashid, M. H., (2007), Motor drives, Chapter 33 in: Power Electronics Handbook: Devices, Circuits, and Applications, Second Edition, ISBN-13: 9780120884797, Academic Press, 2007.

Rowan, T. M., Kerkman, R. J. \& Leggate, D. (1982), A simple on-line adaptation for indirect field orientation of an induction machine, Proceedings of IEEE IAS Annual Meeting Conference, pp. 604-609, 1982.

Santiago, J. \& Bernhoff, H. (2010), Comparison between axial and radial flux PM coreless machines for flywheel energy storage, Journal of Electrical Systems, Issue 2, Vol. 6, (June 2010), ISSN 1112-5209. 
Srilad, S., Tunyasrirut, S. \& Suksri, T. (2007), Implementation of a scalar controlled induction motor drives, Proceedings of 2006 SICE-ICASE International Joint Conference (IEEE Cat. No. 06TH8879), p 6, 2007.

Stulrajter, M., Hrabovcova, V. \& Franko, M.(2007), Permanent magnet synchronous motor control theory, Journal of Electrical Engineering, Vol. 58, No. 2, pp. 79-84, 2007.

Su, G. J. \& Adams, D. J (2001), Multilevel DC link inverter for brushless permanent magnet motors with very low inductance, Proceedings of IEEE Industry Applications Society Annual Meeting, pp. 829-834, 2001.

Sun, X. D., Koh, K. H., Yu, B. G. \& and Matsui, M., (2009), Fuzzy-Logic-Based V/f Control of an Induction Motor for a DC Grid Power-Leveling System Using Flywheel Energy Storage Equipment, IEEE Trans. on Industrial Electronics, Vol. 56, No. 8, 2009.

Takahashi, I. \& Noguch, T. (1986), A new quick response and high efficient control strategy for an induction motor, IEEE Trans. Industrial Applications, Vol. 22, pp. 820-827, 1986.

Tazil, M., Kumar, V., Bansal, R.C., Kong, S., Dong, Z.Y. \& Freitas, W. (2010), Three-phase doubly fed induction generators: an overview, IET Electric Power Applications, Vol. 4, No. 2, pp. 75-89, Feb. 2010.

Toufouti, R., Meziane, S. \& Benalla, H. (2006), Direct Torque Control for Induction Motor Using Fuzzy Logic, ACSE Journal, Vol. 6, No. 2, June 2006.

Toufouti, R., Meziane, S. \& Benalla, H. (2007), Direct torque control for induction motor using intelligent techniques, Journal of Theoretical and Applied Information Technology, pp. 35-44, 2007.

Touma-Holmberg, M. \& Srivastava, K. (2004), Double winding, high-Voltage cable wound Generator: steady-State and fault analysis, IEEE Trans. on Energy Conversion, Vol. 19, No. 2, pp. 245-50, June 2004.

Valenciaga, F \& Puleston, P. F. (2007), Variable Structure Control of a Wind Energy Conversion System Based on a Brushless Doubly Fed Reluctance Generator, IEEE Trans. on Energy Conversion, Vol. 22, No. 2, 2007.

Wallmark, O., Kjellqvist, P. \& Meier, F. (2009), Analysis of axial leakage in high-speed slotless PM motors for industrial hand tools, IEEE Trans. on Industry Applications, Vol. 45, No. 5, pp. 1815-20, Sept.-Oct. 2009.

Wu, J., Wen, J., \& Sun, H. (2009), A New Energy Storage System Based On Flywheel, Proceedings of IEEE Power E Energy Society General Meeting (PES), pp. 1-6 , 2009, ISSN: 1944-9925.

Xu, X., De Doncker, R. \& Novotny, D. W. (1988), A stator flux oriented induction machine drive, Proceedings of IEEE Power Electronics Specialists Conference, pp. 870-876, 1988. 


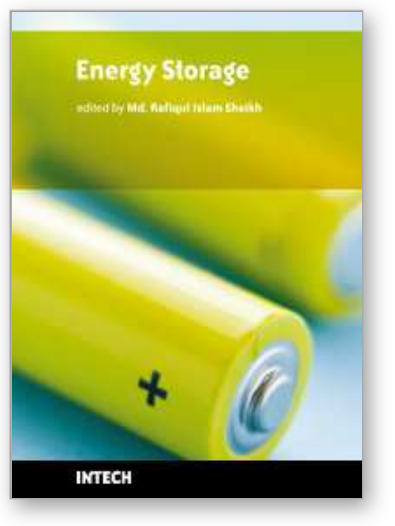

\author{
Energy Storage \\ Edited by Rafiqul Islam Sheikh
}

ISBN 978-953-307-119-0

Hard cover, 142 pages

Publisher Sciyo

Published online 27, September, 2010

Published in print edition September, 2010

Electricity is more versatile in use because it is a highly ordered form of energy that can be converted efficiently into other forms. However, the disadvantage of electricity is that it cannot be easily stored on a large scale. One of the distinctive characteristics of the electric power sector is that the amount of electricity that can be generated is relatively fixed over short periods of time, although demand for electricity fluctuates throughout the day. Almost all electrical energy used today is consumed as it is generated. This poses no hardship in conventional power plants, where the fuel consumption is varied with the load requirements. However, the photovoltaic and wind, being intermittent sources of power, cannot meet the load demand all of the time. Wherever intermittent power sources reach high levels of grid penetration, energy storage becomes one option to provide reliable energy supplies. These devices can help to make renewable energy more smooth and reliable, though the power output cannot be controlled by the grid operators. They can balance micro grids to achieve a good match between generation and load demand, which can further regulate the voltage and frequency. Also, it can significantly improve the load availability, a key requirement for any power system. The energy storage, therefore, is a desired feature to incorporate with renewable power systems, particularly in stand alone power plants. The purpose of this book is twofold. At first, for the interested researcher it shows the importance of different Energy Storage devices, but secondly, and more importantly, it forms a first attempt at dissemination of knowledge to the wider non-expert community who may wish to consider Energy Storage device for specific application. Thus this book will be helpful to provide an indication of the tools necessary for an assessment to be made Energy Storage device more powerful.

\title{
How to reference
}

In order to correctly reference this scholarly work, feel free to copy and paste the following:

Juan De Santiago and Janaina Goncalves de Oliveira (2010). Electric Machine Topologies in Energy Storage Systems, Energy Storage, Rafiqul Islam Sheikh (Ed.), ISBN: 978-953-307-119-0, InTech, Available from: http://www.intechopen.com/books/energy-storage/electric-machine-topologies-in-energy-storage-systems

\section{INTECH}

open science | open minds

\section{InTech Europe}

University Campus STeP Ri

Slavka Krautzeka 83/A

51000 Rijeka, Croatia

\section{InTech China}

Unit 405, Office Block, Hotel Equatorial Shanghai

No.65, Yan An Road (West), Shanghai, 200040, China

中国上海市延安西路65号上海国际贵都大饭店办公楼405单元 
Phone: +385 (51) 770447

Fax: +385 (51) 686166

www.intechopen.com
Phone: +86-21-62489820

Fax: +86-21-62489821 
(C) 2010 The Author(s). Licensee IntechOpen. This chapter is distributed under the terms of the Creative Commons Attribution-NonCommercialShareAlike-3.0 License, which permits use, distribution and reproduction for non-commercial purposes, provided the original is properly cited and derivative works building on this content are distributed under the same license. 